\title{
How Big Data Ecosystem Changes Cloud Services: A Design Science Perspective
}

\author{
Chien-Hung Liu1, Sheng-Chi Chen1, Pei-Hung Hsieh² \\ ${ }^{1}$ Department of Management Information System, National Chengchi University, Taipei, Chinese Taipei \\ ${ }^{2}$ Institute for Information Industry, Taipei, Chinese Taipei \\ Email: claude.liu@gmail.com, forcsc1001@gmail.com, mikahsieh@gmail.com
}

Received 9 May 2015; accepted 11 July 2015; published 14 July 2015

\begin{abstract}
With the trend of digital economy, cloud services and its ecosystem have developed and matured. Another fast-growing trend, data Economy and big data, changes the way how cloud services create value. This research aims to explain the evolution of cloud service development during the big data era in the design science perspective. An ecosystem model with three roles is proposed to show the big data ecosystem and the relationships with the development of cloud services. Currently, we use a cloud service case to explain the proposed model and believe that the proposed model can inspire further research on cloud and big data ecosystem.
\end{abstract}

\section{Keywords}

\section{Big Data, Cloud Service, Ecosystem, Design Science, Cloud Computing}

\section{Introduction}

From early 1990, different emerging information technologies continue to change the operations of information society. The behavior of customers keeps evolving with new information technology application. For example, as cloud computing application develops, massive cloud services have developed for customers to satisfy mobility needs. The increasing popularity of cloud services generates huge amounts of data into cloud data platforms and leads the trend of big data application.

Many research institutions have pointed out the trend that big data will be a rapid growth market and move current economy towards a thriving data-driven economy. Gartner conducted a large scale survey study that covered 2000 types of information technologies and 119 trendy areas [1]. Based on findings, the study sets the tune that "digital business" is the core element among emerging technology development life cycle. Therefore, industries start to value the use of data for business opportunities. Government and businesses are pondering hard on how to explore the trends and insights from big data so that they can better implement policies and develop business [2]. The design of cloud services is influenced by new knowledge and technology. In this sense, the new big data ecosystem would change the existing and future cloud services for new value creation. This research aims to propose a model to discuss how cloud service will evolve in big data ecosystem in design science perspective. 
This paper is organized as follows. The basic concepts of big data and data economy are provided in Section 2 . The big data ecosystem is described in Section 3. Section 4 then discusses the evolving cloud services in big data ecosystem using a case scenario. Implication and conclusion are summarized in Sections 5 and 6.

\section{Big Data and Data Economy}

Big data technology can extract valuable information from massive and disordered data and discover knowledge that could not have been able to. Big data analytics use analytical approaches to help more businesses identify hidden business opportunities. Today people at different corners of society start to feel the power of big data. Noteworthy, data generated from clouding computing equipments and devices, such as social media data, mobile and geo-location data, sensory data from IoT, and innovative use of data, such as crowd sourcing and its innovation model will be the next golden opportunities for businesses [3] [4]. Big data, as implied by the name, means that large volume of data being extracted, transformed, processed and analyzed through information technology to become useful information for understanding phenomena, trend prediction, and decision making.

Many studies think that the characteristics of big data are high volume, high velocity, and high variety and require new methodology to process data to discovery insights for decision making. 3Vs definition (volume, variety, velocity) is the most widely accepted views so far [2] [4] [5]. Other researches add variability, veracity or value. Viktor Mayer-Schonberger of Oxford University in UK and Kenneth Cukier of The Economist provide a different point of view in their recent book "Big Data: A Revolution That Will Transform How We Live, Work and Think." They point three conclusions: 1) big data should size all data, rather than only samples; 2) data volume is far more important than quality; 3) big data analysis should focus on finding correlation, rather than casual relationship [6].

Mind Commerce predicts that big data would market value would reach 12 billion US dollars in 2013 as businesses quickly adapt big data services. The big data market will remain robust on its development with a compound annual growth rate (CAGR) of 46\% between 2015 and 2020 and a market size of 190 billion US dollars by 2020 [7]. This proves the needs for new data source drives a new "data economy" business model. When data is seen as a commodity, business or individual is willing to pay for the data for better product/service development or consumption. For example, business can use big data and technology to develop new product or service, improve decision making quality, customer services or operation efficiency.

Consequently, Big Data can be described as data collected from all kinds of sources and its volume is hard to handle via traditional information technology. However, there exists another augment that the point is not on how big the data volume is but what value can be found from data. After all, how big is considered big is difficult to be defined.

\section{The Big Data Ecosystem}

The digital ecosystem which describes the relationships and interactions between firms, technology and knowledge is inspired from biological ecosystems [8]. Likewise, Big Data Ecosystem (Figure 1) is consisted of three important elements which are identified by this study as business, data and analysis. Big data value comes from technologies developed to collect and analyze data networked crossing equipments, systems and services. There are three key roles, Data Owner, Application Audience, and Technology Developer, identified in the big data ecosystem [9] [10].

In the big data ecosystem, data owners are the key role which owns data and power to define how services to offer, such as business in private sectors or institutions in public sectors. To provide fuels into big data ecosystem, this role could leverage crowd sourcing or other forms to open and share data that contain potential values for industry innovation. Application audiences can utilize data to develop new innovative services or models of value and help industries develop their capability of using data. Application audiences also helps government and research institutions their concepts and assess their feasibilities. This relationship not only formulates a good partnership model that directs how industries can feedback to governments and research institutions but also helps them grow experience so that overall data value and quality can be enhanced. Technology developers in the ecosystem utilize data from data owners to develop services to satisfy application audiences via open API. This role expedites to extract more knowledge, intelligence form data gold mine and gradually accumulate more industry success use cases that in turn help ecosystem development. 


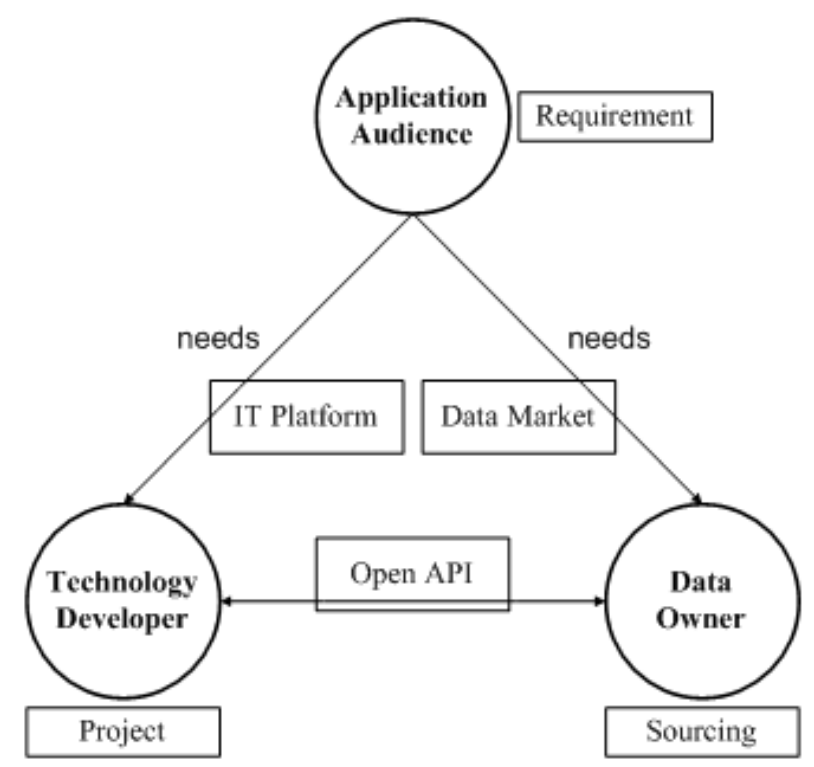

Figure 1. The big data ecosystem.

\section{Cloud Services in Big Data Ecosystem}

Traditionally, technology developers develop cloud services according to the needs of application audiences via IT platform such as SaaS, PaaS and IaaS platform. For example, customers can book their seats in a movie theater on their mobile phone, or use mobile application to get weather information or understand traffic flow now in a highway. The relationships between technology developers, application audiences and data owners can be described in Figure 2. In comparison with Figure 1, the role of data owners is less important in the big data ecosystem nowadays. Therefore, in a cloud service platform such as the android market or apple store, customers can find similar services easily.

From design science viewpoint [11], a cloud service developed to solve business problems based on relevant theories and methodologies should create artifacts. Traditional cloud services have only little contribute to environment and knowledge base because they can only provide data or information to customers. In other words, these cloud services can be replaced by others easily without providing the insights or analysis from data or information. On the other hand, if a cloud services provides not only traffic conditions in every highway, but also can predict traffic flow in a specific period using big data analysis. Customers can prepare their travel plan and have more chances to avoid traffic jam than traditional services. The artifacts from this cloud service would be unique from its service provision and can have significant contribution to the application environment and knowledge base. Therefore, in the big data era, the development of cloud services would have more interactions to data and data owners than before. The relationships among users, developer and data would evolve to the model described in Figure 1.

\section{Implication}

To increase the service value of cloud services for customers, the developers of cloud services should discover the insight of information for customers instead of information provision. The new generation of cloud services would have tightly connections to the trend of big data. Therefore, how to overcome the topics in the big data ecosystem would be important to the development of new generation of cloud services. We list some related topics in the big data ecosystem in Table 1 and may be useful for the future research direction.

\section{Conclusion}

In this research, we use a case to explain the evolution of cloud services by the proposed big data ecosystem. We have pointed out how and why traditional cloud service should be evolved with the trend of big data. For the cloud service provides choosing to follow the big data trend, they should be clear enough about the big data 


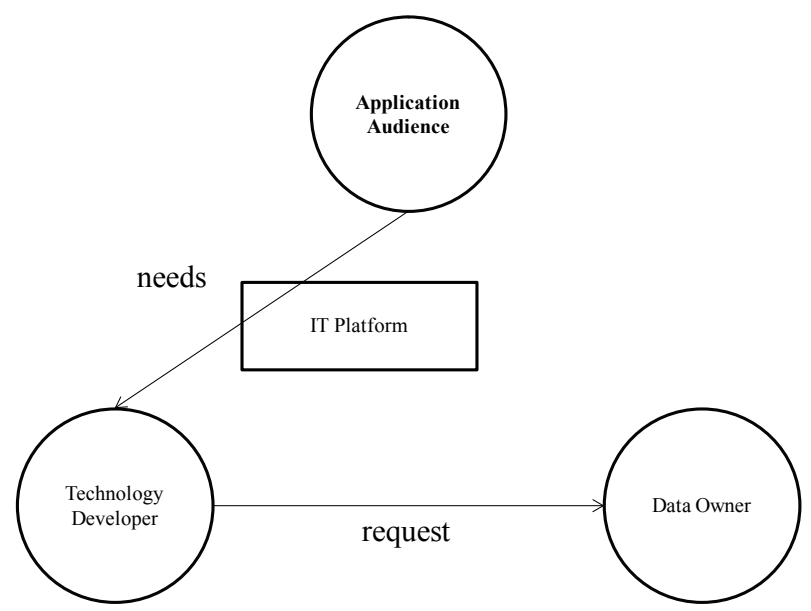

Figure 2. Traditional cloud service provision.

Table 1. Topics in big data ecosystem.

\begin{tabular}{|c|c|}
\hline Role & Key Issue \\
\hline \multirow{3}{*}{ Data Owner } & $\begin{array}{l}\text { - Most structured or unstructured big data still exists big enterprises and internet service industry, } \\
\text { especially consumer-facing industries }\end{array}$ \\
\hline & $\begin{array}{l}\text { - Challenges for economizing Open Data are many: data authorization, quality, format, update and cost } \\
\text { to develop data economy }\end{array}$ \\
\hline & - Regulations tend to be scattered and complex \\
\hline \multirow{3}{*}{ Application Audience } & - Cultures, attitudes, and conduct guidance required for being data-driven are not popular \\
\hline & - Co-operations crossing industries are rare \\
\hline & - Opportunity to acquire capitals and facilities are insufficient \\
\hline \multirow{4}{*}{ Technology Developer } & $\begin{array}{l}\text { - Domain experts are scattered around different places. Besides, their visionability may not high } \\
\text { enough to have rich experience }\end{array}$ \\
\hline & - The model working with entrepreneurs for innovation is not established \\
\hline & - New tools and skills for big data are not familiar on the market and need more exposure \\
\hline & - Existing enterprise-wide tools are difficult to be integrated with Big Data application \\
\hline
\end{tabular}

positioning and value what they are pursuing so that resources can be allocated properly to seize opportunities. Cloud service providers, customers and data owners would co-create new service value and artifacts to contribute to the evolution of the ecosystem.

\section{References}

[1] Gartner Gartner Survey Reveals That 73 Percent of Organizations Have Invested or Plan to Invest in Big Data in the Next Two Years. http://www.gartner.com/newsroom/id/2848718

[2] Kim, G.-H., Trimi, S. and Chung, J.-H. (2014) Big-Data Applications in the Government Sector. Communications of the $A C M, 57,78-85$. http://dx.doi.org/10.1145/2500873

[3] Liu, H. (2013) Big Data Drives Cloud Adoption in Enterprise. IEEE Internet Computing, 68-71. http://dx.doi.org/10.1109/MIC.2013.63

[4] Mind Commerce (2014) M2M/IoT, Cloud, Big Data and Analytics: Market Dynamics and Opportunities. Mind Commerce Publishing.

[5] Ularu, E.G., Puican, F.C., Apostu, A. and Velicanu, M. (2012) Perspectives on Big Data and Big Data Analytics. Database Systems Journal, 3, 3-14.

[6] Mayer-Schönberger, V. and Cukier, K. (2014) Big Data: A revolution That Will Transform How We Live, Work, and Think. Eamon Dolan/Mariner Books.

[7] Mind Commerce (2014) The Big Data Market: Business Case, Market Analysis and Forecasts 2015-2020. Mind Commerce Publishing. 
[8] Nachira, F. (2012) Toward a Network of Digital Business Ecosystems Fostering the Local Development. http://www.europa.eu.int/information_society/topics/ebusiness/godigital/sme_research/index_en.htm

[9] Shin, D.-H. and Choi, M-J. (2014) Ecological Views of Big Data: Perspectives and Issues. Telematics and Informatics, 32, 311-320. http://dx.doi.org/10.1016/i.tele.2014.09.006

[10] Demchenko, Y., de Laat, C. and Membrey, P. (2014) Defining Architecture Components of the Big Data Ecosystem. Proc. of 2014 International Conference on Collaboration Technologies and Systems, IEEE Press, 104-122. http://dx.doi.org/10.1109/cts.2014.6867550

[11] Hevner, A.R., March, S.T., Park, J. and Ram, S. (2004) Design Science in Information Systems Research. MIS Quaterly, 28, 75-105. 